\title{
Strategies for Electricity with Zero Carbon Emissions at 2050 using the water Management at Mallorca-Menorca Electric system.
}

Andreu Moià-Pol ${ }^{1}$, Vincent Canals ${ }^{1}$ and Víctor Martínez-Moll ${ }^{1}$

${ }^{1}$, Energy Engineering Research Group (GREEN)

Physics Department, Universitat de les Illes Balears

ctra. Valldemossa, km 7,5, E-07122, Palma de Mallorca, Illes Balears, Spain

Phone/Fax number:+0034 971171374, e-mail: andreu.moia@uib.es, vincent.canals@uib.es, victor.martínez@uib.es

\begin{abstract}
Energy import dependence in Mallorca and Menorca Islands is about the $97 \%$. The periods of drought creates water problems and increase the energy consumption, some Island's need as well to import water. The increase in energy and water consumption, in $\mathrm{CO}_{2}$ emissions due to increase of the population and the tourism, is not an environmentally and economically a sustainable scenario for the climate change. The aim of this study is to identify strategies to reduce energy electric consumption and greenhouse gas emissions, designing a target scenario featuring "zero $\mathrm{CO}_{2}$ emissions" and "100\% renewable energies" with the water management. The $\mathrm{CO}_{2}$ emissions and water consumption in the Balearic Islands studied will be used in this study. The results show possible strategies and infrastructure changes than can reduce the $\mathrm{CO}_{2}$ emissions to zero and find out future net zero energy scenarios with the water consumption.
\end{abstract}

\section{Key words}

Hydropower, Renewable energy, Desalination, Zero Carbon Emissions.

\section{Introduction}

The energy and water are two of the most important national issue; they generate most of the conflicts and wars over the world. Climatic change, brought about notably by the burning of fossil fuels, is a serious threat to all our countries and to the rest of the world, in particular the poorest countries. Climate change it's increasing the desertification in the southern countries. The increase of the prices of the fossil fuel it's making less competitive the countries and areas with a high consumption. A problem of the Balearic Islands is that its energy model is based on imported fossil fuels, almost the $97 \%$ comes from imported fossil fuels, with only the $3 \%$ coming from Renewable Energy Sources in these included the biomass and the waste [1]. Two thirds of electricity generation relies on fossil fuels [2].

Some Islands are close to archive this goal; the island Eigg from Scotland is the first island to be $100 \%$ energy efficient and reliant exclusively on renewable resources. El Hierro in Spain, where a wind power plant installed together with a reversible hyro-electric power plant store the excess energy in water, which later on provides energy in the absence of wind, it's near to arrive to zero emissions.

Mallorca and Menorca, with a population of 950.600 (2015)[9], the population at summer arrives to 1.500 .000 . The Island's usually they have another problem, the water, especially at the Mediterranean Islands, that only rains some months during the year, and when the consumption it's higher it's not raining. It's very important to have large storage systems in order to pass the summer, where they have few rain and increase of population due to the tourism. The big advantage is during these months the solar radiation it's high, creating synergies with water and energy we can design zero emissions scenarios.

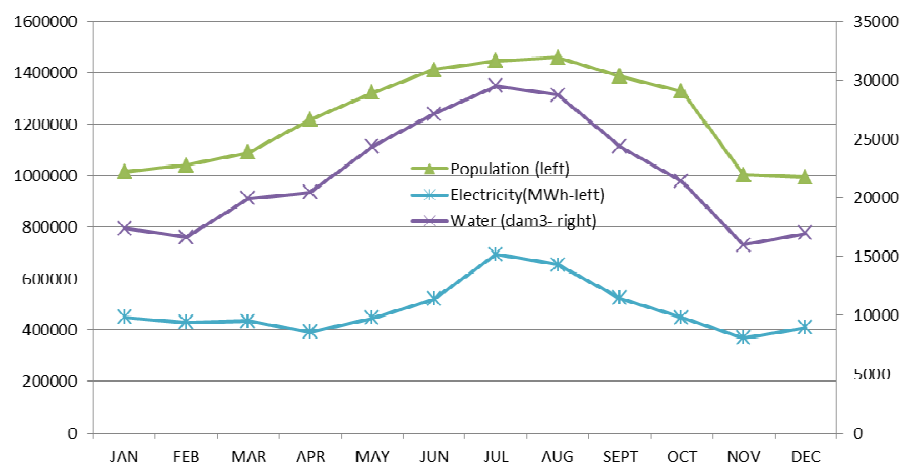

Fig. 1. Population ( including the visitors) and Electricity Consumption (left axis), Water ( right axis) by months in the Mallorca and Menorca Island's.

\section{Water Management}

Most of the water of Mallorca and Menorca is coming from subterranean source or water storage (cistern and pools), big reservoirs, all this water it's rain water storage during all the year (especially winter and autumn) or from other years. Serra of "Tramuntana" has the biggest reservoir in Mallorca, with two lakes; Cuber and Gorg Blau, artificial lakes finished in 1972 for cover the increase of water consumption with the first touristic rise at the Bay of Palma. They have a capacity of $4.64 \mathrm{hm}^{3}$ and $7.34 \mathrm{hm}^{3}$. They have an altitude of 635 meters and 775 respectively of highness and at this moment there isn't any water turbine to take profit of the big amount of potential energy, on the opposite there is a system to reduce the speed of the water before arrives of the treatment plant.

These big infrastructures weren't enough for drought and increase of population and they have to be increased in the 90 's, actually they only cover the $35 \%$ from all the water consumption of Palma (the capital of the Autonomous Community). 


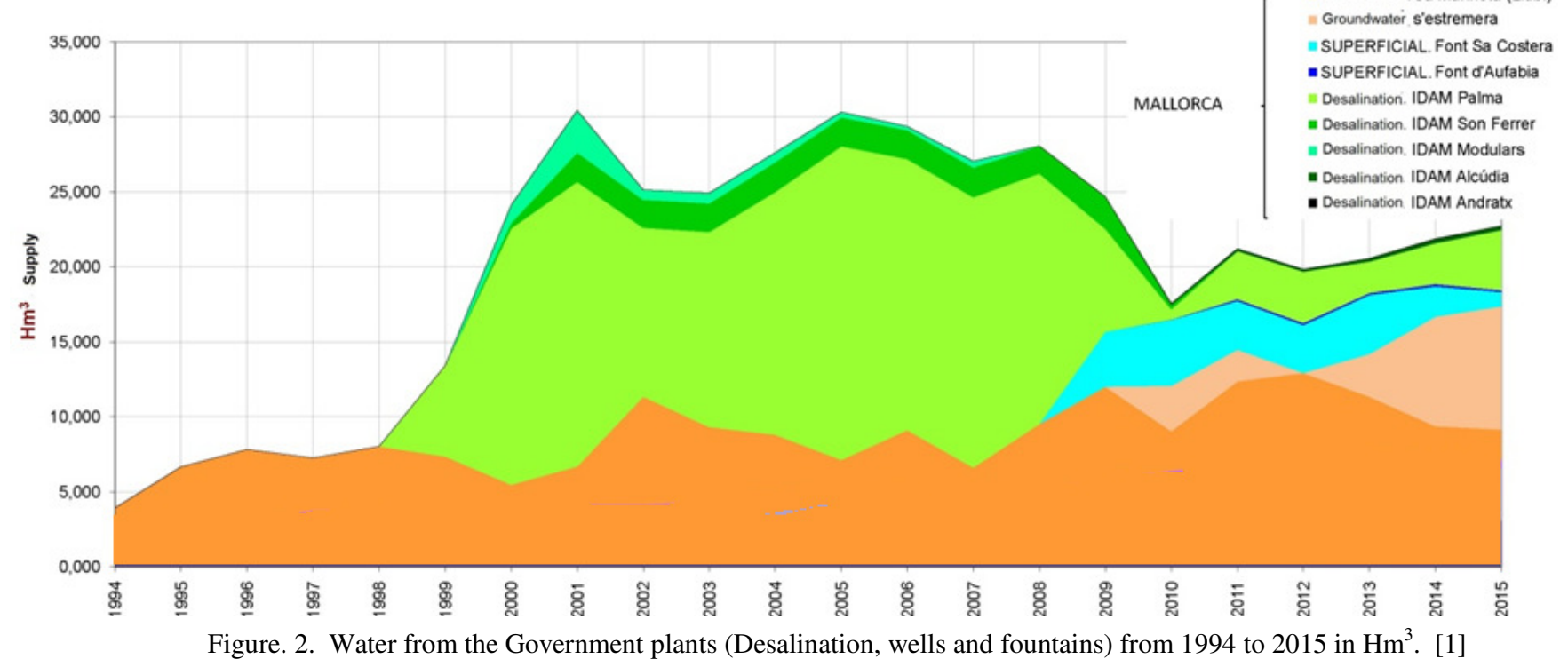

Palma is the largest city of the Balearic Islands, with a population of 400.578 (2015)[9]. The last 15 years have been built several desalination plants in the biggest cities of the islands, in order to provide the months and periods of drought. This plants the use membranes with sea water, spending from 4 to $17 \mathrm{kWh} / \mathrm{m}^{3}$, depending of the capacity of the plant and fraction production [10].

Table I. - Desalination plants in Mallorca with max capacity.

\begin{tabular}{|c|c|c|c|}
\hline Mallorca & $\mathbf{m}^{\mathbf{3}} / \mathbf{d a y}$ & $\mathbf{h m}^{\mathbf{3}} / \mathbf{y e a r}$ & $\mathbf{M W h} / \mathbf{d a y}$ \\
\hline Palma & 64800 & 23.65 & 648 \\
\hline Calvià & 5500 & 2 & 55 \\
\hline Andratx & 14000 & 5.11 & 140 \\
\hline Alcúdia & 14000 & 5.11 & 140 \\
\hline & $\mathbf{9 8 3 0 0}$ & $\mathbf{3 5 . 8 7}$ & $\mathbf{9 8 3}$ \\
\hline
\end{tabular}

Since 1998 the Desalination plants are necessary for cover all the water consumption, some years with a lot of rain or with economic problems has been reduced [1].

The desalinization energy price it's higher that the rest of the sources of in Spain goes from $0.2 € / \mathrm{m}^{3}$, to $2.55 € / \mathrm{m}^{3}$, depending of the tariff and the energy efficiency of the plant. The extra cost of the electricity production in Mallorca-Menorca it's covered by the total cost of the electricity in Spain, this reduce the real cost, that will be two or three times bigger. The prices of electricity goes from $0,07 € / \mathrm{kWh}$ to $0,20 € / \mathrm{kWh}$, depending of the period, annual consumption and month. The biggest difference it's at the mainland all the month of august it's valley period and in the Balearic Island's it's March, due to the increase of consumption at summer.

The final prices of water in Palma goes from 0,5714 to $5,1199 € / \mathrm{m}^{3}$ [8], (according with the table II) depending of the building and monthly consumption. With renewable energy the price could be lower, and give the advantage to do it when there is overproduction, in this case you could solve one of the biggest problems of the renewable energies, the production vs. the consumption.
The desalination has big energy consumption, with another impact in the Climate change, for this reason in the future this plants they should have to be with Renewable energies. They could arrive to increase the electric consumption a $10 \%$ if they work full capacity at the peak hour.

As a consequence of scarcity of water resources and increasing of water consumption in many parts of the world, in recent years there were a growing interest on improve water management, including seawater desalination, reduction of loses by pipes in water supply, and sensibilities campaign to the population, the installation of individual counters and the reuse of treated wastewater [7].

Table II. -Prices of water in Palma

\begin{tabular}{|c|c|}
\hline Consumption & Water Prices $\left[€ / \mathrm{m}^{3}\right]$ \\
\hline 1 to $10 \mathrm{~m}^{3}$ & 0.5714 \\
\hline 11 to $20 \mathrm{~m}^{3}$ & 0.7801 \\
\hline 21 to $40 \mathrm{~m}^{3}$ & 1.2589 \\
\hline 41 to $80 \mathrm{~m}^{3}$ & 2.7879 \\
\hline more to $81 \mathrm{~m}^{3}$ & 5.1199 \\
\hline
\end{tabular}

Future scenarios go from reduction water consumption and increase the rain storage in all the buildings. New laws and directives needs to be apply in water management, in order to make buildings with more water efficiency, and find new resource (rain), recycled water,... The actual water reservoirs that have in the mountains have a big potential of hydropower energy (theoretical peak power near to $300 \mathrm{MW}$ ), the pipes are very old and need a change and improve, in this way it can be integrated with the energy system, with a reversible hydropower system. 


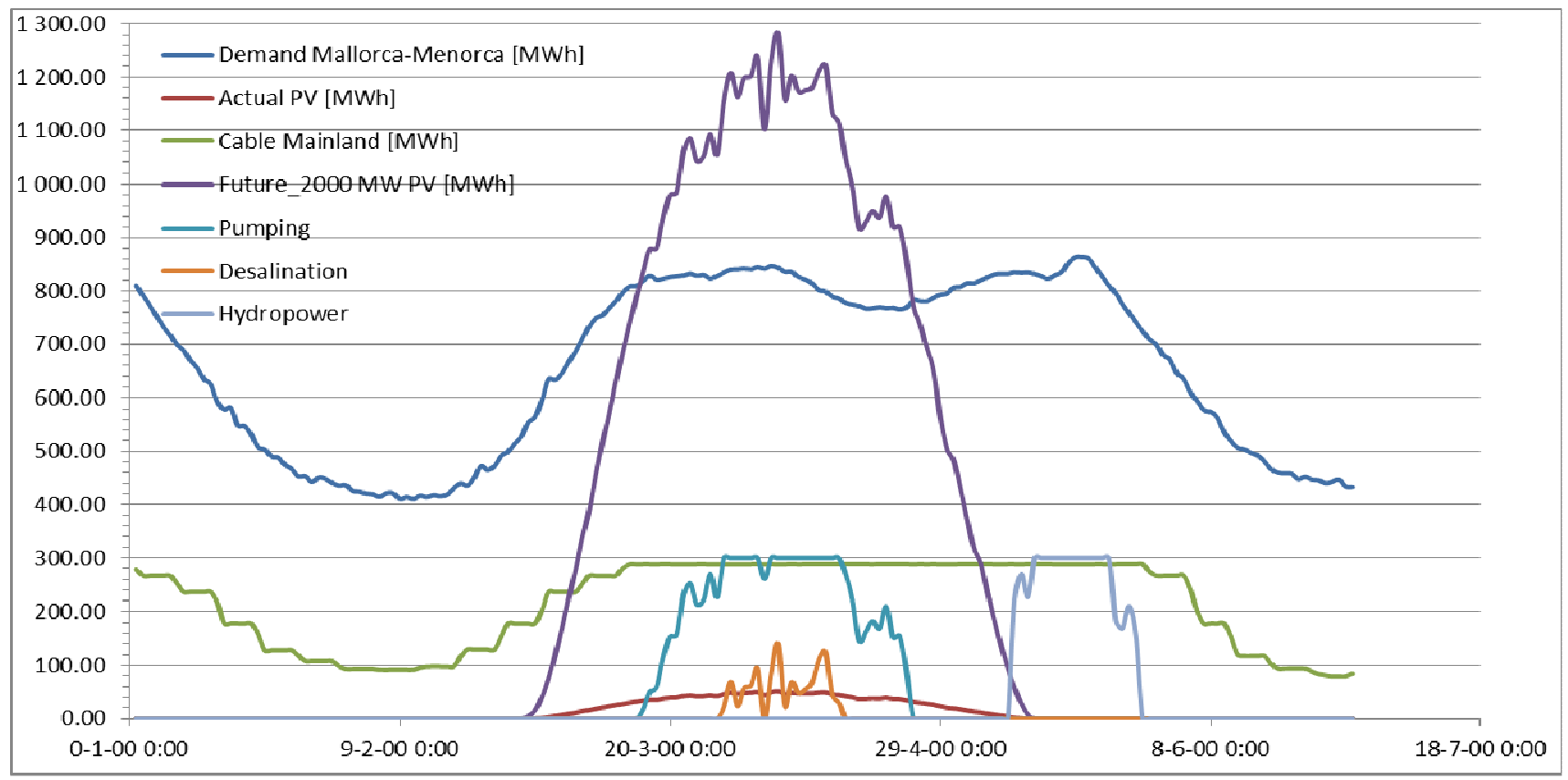

Fig. 3. Future Electric RE with desalination at summer in Mallorca-Menorca Electric system with a real day (August 12 $2^{\text {th }}$ of 2016).

\section{Electric System}

A problem in the Mallorca-Menorca electric system, and in the rest of the Spanish Islands, is that its energy model is based on imported fossil fuels. The solar and wind energy they only have the $1 \%$ of the total energy production. The Mallorca-Menorca system has been connected to the mainland with 2 submarine cables $250 \mathrm{kV}$ High Voltage Direct Current (HVDC) with a maximum power capacity of $400 \mathrm{MW}$, covering a total distance of $250 \mathrm{~km}$ in 2012 . Actually this provides about $30 \%$ of the energy [2], there is a future project to increase the cable for increase the power, but it's not approved yet. Balearic Island's with an installed power of $2490 \mathrm{MW}$ and $80 \mathrm{MWp}$ of PV installed, $20 \mathrm{MWp}$ of Waste power plant, $3 \mathrm{MWp}$ of wind power and peak consumption of $1205 \mathrm{MW} \mathrm{[1][2].}$ The main generation system is composed of two thermal power plants responsible for, respectively, $72 \%$ and the $12 \%$ of the demand on each of the two island subdivisions, and a combined cycle central that started to use natural gas five years ago, in order to reduce the $\mathrm{CO}_{2}$ emissions and increase the efficiency. The rest is generated in 4 small distributed generation plants. The principal thermal power plant, with a nominal power of $510 \mathrm{MW}$, constitutes the basis of the system; it's still working with coal, the most contaminant fossil fuel. The other Power Plants assume the peaks of demand in the islands. The described production model produces a high amount of $\mathrm{CO}_{2}$ emissions, because it is based on coal turbines. The use of coal as fuel also has an important effect, in the production of acid rain. Actually the PV produces some hours only the $10 \%$, with annual production of $2 \%$. The government's Energy Planning Project intends to reduce global energy consumption by $3 \%$, and increase by $10 \%$ the use of Renewable Energy Sources (RES) at 2020 and to $100 \%$ in 2050.

\section{Zero emission strategy for water and electric consumption}

One of the most important means to increase efficiency and to reduce water consumption and $\mathrm{CO}_{2}$ emissions is to organize and rationalize the energy systems and water systems, mainly by the rational production and consumption of the energy produced and the use of endogenous energy and water sources.

In general, the islands present great potentiality in renewable energy sources, such as solar, wind, geothermal, biomass, hydro and wastes.

Historically the water management was present in the old constructions, with cisterns and rain watering reservoirs. Seawater desalination process can also be used for energy storage [3], creating a synergy with renewable energies.

Future scenarios go from reduction of energy and water consumption and increase the renewable energies and rain storage. Mallorca have actually facilities of solar, wind and wastes, and a big potential in hydro, biomass and shallow geothermal.

The actual water reservoirs the big potential of hydropower energy (theoretical peak power near to 300 MW), there is a pumping station for transfer water from one dam to the other with a flow of $0,5 \mathrm{~m}^{3} / \mathrm{s}$. The peak flow could arrive to $92,70 \mathrm{~m}^{3} / \mathrm{s}$ [8]. In the last 30 years only two times have been over to the $100 \%$ of the capacity, in the 80's and this winter. Storage energy can be add to the system, adding a new reservoir in the energy system, like the existing mine of Can Negret ( between Lloseta and Alaró), actually used for extract materials for a Cement Factory. This potential dam has an altitude of 146 and a potential storage of 7,34 $\mathrm{Hm}^{3}$. The cost of adapt this mine like a reservoir will be very low, and according to the Spanish law the owner has to restore it and give back to the original state, with this cost it could be pay this adaptation.

With this new infrastructure we will increase the water storage of the island ( with more storage from the rain), and it could be make a reversible hydro-electric power plant store the excess energy in water, which later on provides energy in the absence of wind and water, these plants are common in Spain, due to the droughts. There is a similar system at the Hierro Island but they don't use the water from the municipality, they use desalination water only for storage purpose. 


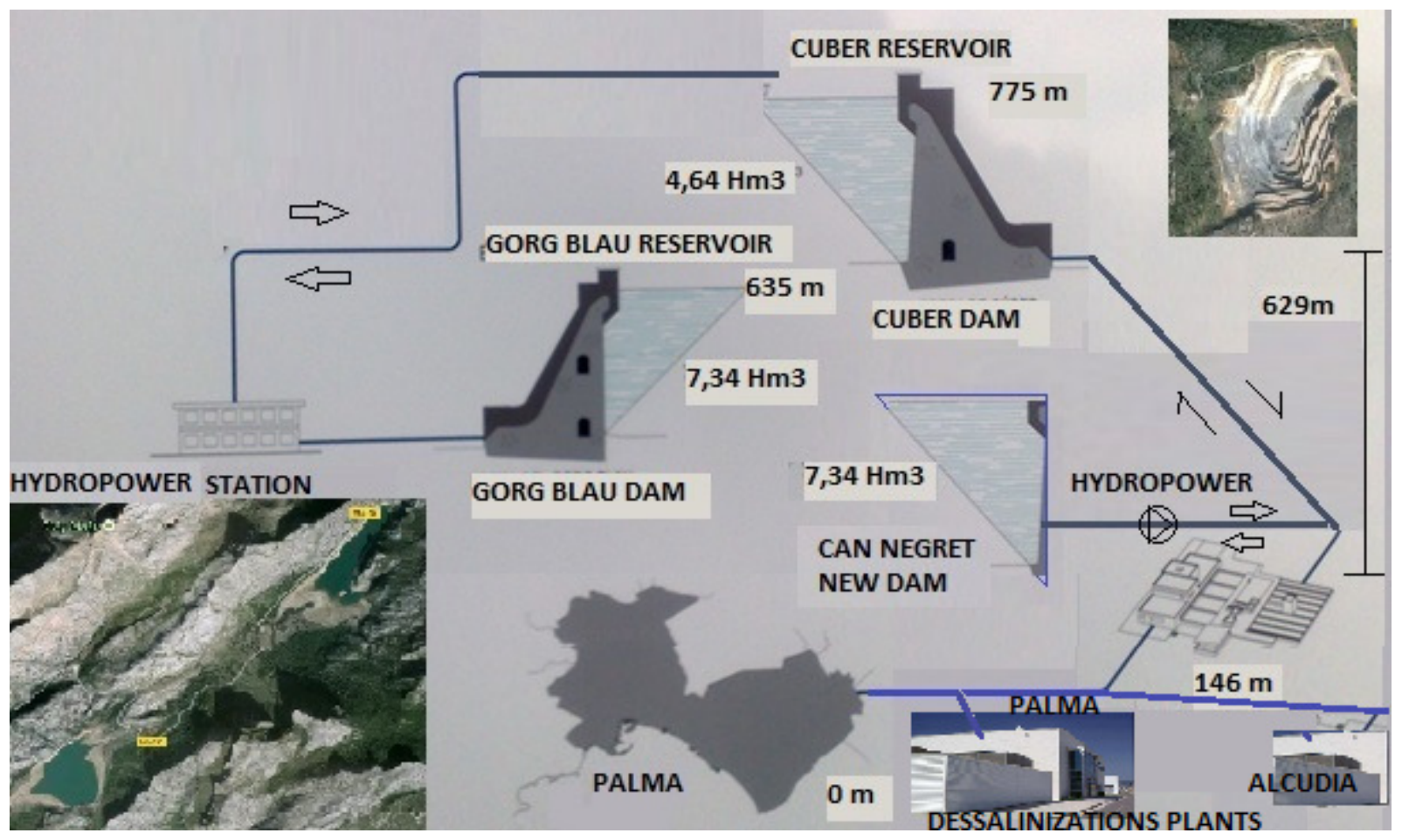

Figure 4. New System connected with the water system in the Mallorca.

This new system combined with other renewable energies (solar thermal, solar photovoltaic, biomass) could be the perfect combination for archive future scenarios of $100 \%$ of RE, adding desalination process, could solve future problems, with water and energy storage from renewable energies sources. The actual electric mix need a big change to become zero emissions, some measures could be; The actual Thermal Coal Plant (510 MW) and Waste Power Plant need a change to Hybrid Thermosolar plants (with concentration technologies) combined with biomass. Increase the PV installed from $80 \mathrm{MW}$ to at least 2000 MW, Increase the wind power from 3 to $400 \mathrm{MW}$ of wind power. The energy could be storage with a reversible hydro-electric power plant. Simulating the system can store the excess energy in water, which later on provides energy in the absence of wind and water, these plants are common in Spain, like the Hierro system.

These changes could transform the unsustainable actual system in a zero emissions scenario, solving as well the periods of drought increasing the desalination plants productions according to the days with over production with RE.

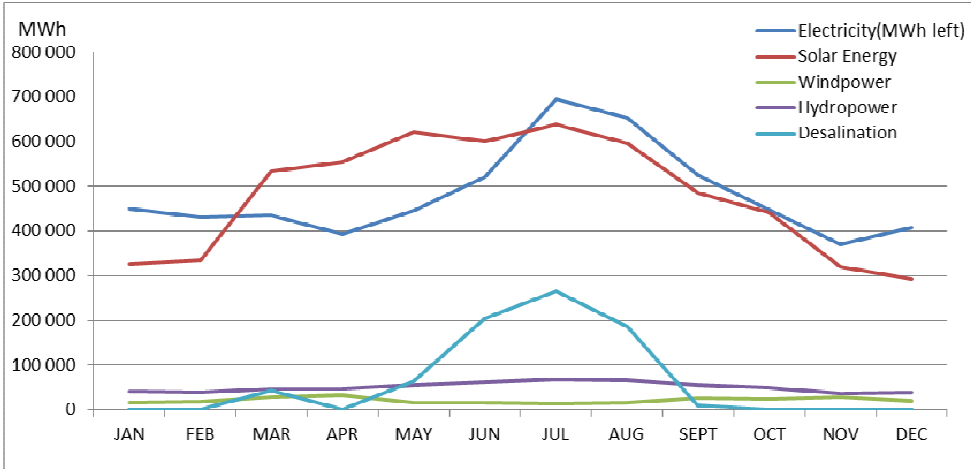

Fig. 5. Future RE with desalination by months in the Balearic Island's

\section{Conclusions}

This new system combined with other renewable energies (Thermosolar, solar photovoltaic, biomass) could be the perfect combination for archive future scenarios of $100 \%$ of RE, adding desalination process, could solve future problems, with water and energy storage from renewable energy. Promoting and investing on renewable energies to combat $\mathrm{CO}_{2}$ emissions is the way to stop to discharge more than 50,000 tons per year with a properly electric mix. The overall zero balance in the Mallorca-Menorca system is overall positive in the order to cover desalination plants.

\section{References}

[1] Govern de les Illes Balears (http://www.caib.es/)

[2] Red Electrica de España http://www.ree.es/

[3] Cipriano Marín, Luis Alves, Arthouros Zervos. Research Group on Energy and Sustainable Development, Mechanical Engineering Department (Lisbon-Portugal) and UNESCO Center of the Canary Islands. 2005. ISBN 84-609-6326-8.

[4] http://www.irena.org/

[5] http://www.hr.undp.org/

[6] A. Moià, B. Rosselló-Batle, Pujol R., V. Martínez. Net zero energy in hotels and touristic areas in the Balearic Islands. Eurosun 2010

[7] Gual, M.; Moia, A. and March, J.G.. Monitoring of an indoor pilot plant for osmosis rejection and greywater reuse to flush toilets in a hotel. Desalination 219 (2008) 81-88

[8] EMAYA (http://www.emaya.es/)

[9] Instituto Nacional de Estadística (http://www.ine.es/)

[10] J.E. Blank, G.F. Tusel, and S. Nisanc. The real cost of desalted water and how to reduce it further. Desalination, Vol 205, nº1-3, pp. 298-311, Feb 2007.. 